\title{
A Case Study On Zoning And Construction Of Roller- Compacted-Concrete Gravity Dams
}

\author{
Qin Genquan ${ }^{1}$, Chen Yangxian ${ }^{2}$ \\ ${ }^{1}$ Jiangxi Provincial Water Conservancy Planning Design and Research Institute, Nanchang 330029, China; \\ ${ }^{2}$ College of Water Conservancy \& Hydroelectric Engineering, Hohai University, Nanjing 210024, China
}

\begin{abstract}
In order to make full use of the concrete strength, reduce the amount of cementitious materials and simplify the temperature control measures, a roller compacted concrete (RCC) dam needs to be zoned reasonably in consideration of locations and working conditions. Taking the RCC gravity dam of Wuxikou hydropower project in Jiangxi province, this article specifies the zonation design, the problems encountered during construction stage and the corresponding measures. The results indicate that the zonation and the construction schemes of the RCC gravity dam can greatly reduce the amount of cementitious materials, improve the level of mechanization in construction, and thus accelerate the construction progress, reduce the project cost. It not only ensures the quality and safety of the project, but also achieves obvious economic benefits. It can be an important reference for zonation design and construction of similar projects.
\end{abstract}

\section{Foreword}

Roller compacted concrete dam (RCC) ${ }^{[1]}$ refers to the dam made of dry concrete, with essentially no slump, which is spread in layers and then compacted by rollers. It is more economical and has shorter construction period, similar to earth \& rock-fill dam, and makes full use of the strength and durability of concrete. According to incomplete statistics, the RCC gravity dams have been rapidly developed at home and abroad ${ }^{[1-10]}$, more than 200 RCC dams have been build in over 20 countries around the world, which are distributed in the regions of tropical and subtropical climate. The first RCC dam is the Willow Creek Dam,52m high, built in 1982 in the United States. The highest RCC gravity dam currently under construction is the Longtan Dam ${ }^{[4,5]}$.Its firstphase dam is $192 \mathrm{~m}$ high, and the second-phase dam is up to $216.5 \mathrm{~m}$. The amount of its roller compacted concrete is 7.5 million $\mathrm{M}^{3}$.

The design of the cross-section of the roller compacted concrete gravity dam is generally made with reference to that of the conventional concrete gravity dam. The dam cross-section should meet the requirements of the water-retaining function and ensure stability. Because of the high strength and better impermeability of the concrete, cross-section of gravity dam is mainly determined by the overall stability of the dam, so the cross-section is generally larger, and the strength and impermeability of inner part of the dam can not be fully utilized. Also, due to the different working conditions, various parts of the RCC dam have different strength, impermeability and frost resistance requirements. For all the above reasons, in order to save and make rational use of cementitious materials, reduce costs, and optimize the performance of the dam, based on the requirement of the function of each part of the dam, we usually use different grades of concrete for different parts of the dam. That is to properly divide the dam into different zones according to their locations and working conditions. At present, the zoning of the concrete of RCC dam has gained attention from many scholars.Wang Bingjun ${ }^{[6]}$ discussed the Zoning of the concrete for the Left-bank RCC Dam of the Tongjiezi Hydropower Station. Li Diguang (2012) ${ }^{[7]}$ analyzed the zoning and mix ratio of the concrete for the dam of Jinanqiao Hydropower Station. Chen Qiang [8] introduced the design of the Guandi Hydropower Station RCC dam's concrete mix proportion and concrete zoning. Zhao Chunju and Zhou Yihong ${ }^{[9]}$ used the zoning of the concrete as the boundary condition for the construction of the Longkaikou RCC gravity dam. Nevertheless, the problems encountered in the construction of the different zones of the RCC dam and its effective solutions are rarely reported.Taking the WUXIKOU hydropower project in Jiangxi Province as an example, this paper focuses on the zoning of RCC gravity dam section, concrete mix proportion, construction problems and their solutions.

\section{Case Study}

\subsection{Overview of the case}

WUXIKOU Project ${ }^{[1,12,13]}$ is an important part of the flood control system of the historic city - Jingdezhen, 
known as the capital of porcelain. Recently completed, It is a large-scale reservoir( Category 2), a Grade-II project, with normal water level of $56 \mathrm{~m}$, dead water level $45 \mathrm{~m}$, flood-control water level limit $50 \mathrm{~m}$, design flood level $62.30 \mathrm{~m}$, check flood level $64.30 \mathrm{~m}$, total reservoir storage capacity 474.7 million $\mathrm{m}^{3}$, regulating storage capacity 133 million $\mathrm{m}^{3}$, power plant installed capacity $32 \mathrm{MW}$. In the layout of the project, along the axis from left to right, the dam is arranged as follows: left-bank non-overflow RCC dam section (163.72 $\mathrm{m}$ in length), surface-overflowing spillway (5 holes, $78.00 \mathrm{~m}$ ), lowhole spillway (6 holes, $108.00 \mathrm{~m})$, power plant section (2 big generator units, 1 small generator unit, $43.10 \mathrm{~m}$ in length), right-bank non-overflow RCC dam section (installation workshop section included, $105.80 \mathrm{~m}$ in length). The total length of the dam is $498.62 \mathrm{~m}$.

The non-overflow dam sections of the Wuxikou project are the roller compacted concrete gravity dams, with crest elevation of $65.5 \mathrm{~m}$, maximum height of 46.80 $\mathrm{m}$, crest width of $8.0 \mathrm{~m}$ (including the corbel's width of $2.1 \mathrm{~m}$ ). The upper part of the upstream dam surface is vertical, the lower part is a 1:0.2 slope, the slope height is $10 \mathrm{~m}$; The upper part of downstream dam surface above the elevation of $59.63 \mathrm{~m}$ is vertical, and the lower part below the elevation of $59.63 \mathrm{~m}$ is a 1: 0.75 slope. In order to improve the stability against sliding of the gravity dam as a whole, a $2.7 \mathrm{~m}$-deep cut-off trench is added at the dam heel. At the trench, a curtain-grouting and drainage gallery is arranged, which is $2.5 \mathrm{~m} \times 3.5 \mathrm{~m}$ (width $\times$ height). The scene of Wuxikou Project is shown in Figure 1. A typical cross section of the non-overflow dam is shown in Figure 2.

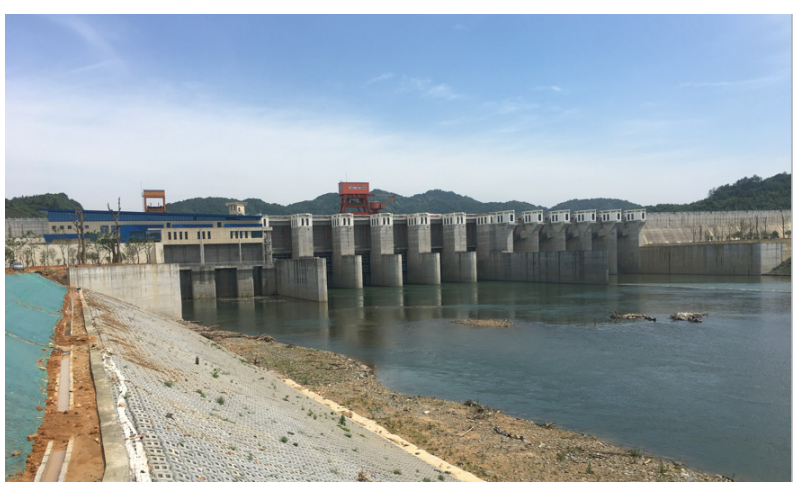

Figure 1. Scene of the WUXIKOU Project.

\subsection{Zoning of Dam Concrete}

The design grade of the concrete of each zone is determined by the climatic conditions of the project site and the height of the dam. WUXIKOU Project is located in the subtropical humid monsoon climate zone, and the dam is a medium height dam. The zoning of dam concrete is made as follows:

(1)The concrete near the crest is designed to be Zone I. In this zone, the working space is relatively narrow, it is not convenient to unload, spread and compact, so use the $\mathrm{C}_{90} 20$ conventional concrete with the 2\#Graded Aggregate, Impermeability Grade W6, and Frost Resistance Grade F50.

(2)The upstream and downstream anti-seepage part is designed as Zone II, using the R90200 RCC concrete with the 2\#Graded Aggregate, Impermeability Grade W6, and Frost Resistance Grade F50. The thickness of this anti-seepage concrete is determined according to the Concrete Gravity Dam Design Code (319-2005 SL) ${ }^{[14]}$, which is $1 / 30 \sim 1 / 15$ of the upstream water head,and meets the minimum thickness requirements for the construction. The thickness of concrete in this project should not be less than $2.5 \mathrm{~m}$, and the thickness of the lower part (with 1:0.2 slope) of the upstream antiseepage zone is gradually increasing with the slope. The advantage of such a design is that the division lines shall be just vertical lines, so as to facilitate the alignment in the construction, and because the thickness of the antiseepage zone at the upstream of the gallery is gradually increasing with the depth of water, it is actually good for anti-seepage.

(3) The inner part of the dam is designed to Zone III. In this zone, the concrete strength and the anti-seepage requirement is relatively low, so use the $\mathrm{R}_{90} 150$ RCC concrete with the $3 \#$ Graded Aggregate, Impermeability Grade W6.

(4) The anti-seepage layer at dam foundation is designed to be Zone IV. For the convenience of leveling and quick compaction of the RCC concrete, the cushion layer at the foundation uses the $\mathrm{C}_{90} 20$ conventional concrete nixed with the 2\# Graded Aggregate, and the concrete at the cut-off trench uses Grout Enriched RCC (GE-RCC).The division line is designed to be a horizontal line, just at the bottom of the Gallery. Due to the trench at the dam heel, the foundation concrete thickness is $1.3 \sim 3.0 \mathrm{~m}$. The concrete Impermeability Grade is W6 and the Frost Resistance Grade is F50.

(5) In order to produce a good appearance and ensure anti-seepage performance, the upstream and downstream face of the dam is designed to be Zone $\mathrm{V}$, at the thickness of $0.5 \mathrm{~m}$, using the $\mathrm{R}_{90} 200$ Grout Enriched RCC (GE-RCC) ( Impermeability Grade W6 and Frost Resistance Grade F50). The scope of Grout Enriched RCC is extended around the water-stops at the transverse joints of the dam, so as to prevent damage to the waterstops by compaction.

The zoned dam section is shown in Figure 2, and the parameters of the concrete materials of each zone are listed in Table 1.

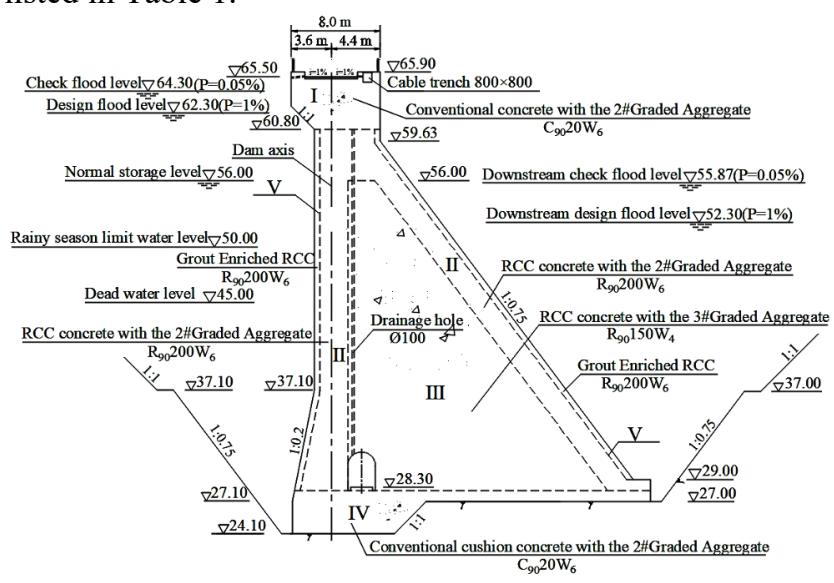

Figure 2. Zoned Dam Section. 
Table 1 . Parameters of the concrete materials of each zone

\begin{tabular}{|c|c|c|c|}
\hline Zone No. & Location & concrete materials & Remarks \\
\hline I & Top & C9020W6、C/W $\leqslant 0.60$ & Conventional concrete \\
\hline II & $\begin{array}{c}\text { Upstream anti-seepage } \\
\text { zone } \\
\text { Downstream anti- } \\
\text { seepage zone }\end{array}$ & $\begin{array}{l}\text { R90200W6、 }(\mathrm{C}+\mathrm{F}) / \mathrm{W} \leqslant 0.50 \\
\text { R90200W6、 }(\mathrm{C}+\mathrm{F}) / \mathrm{W} \leqslant 0.50\end{array}$ & $\begin{array}{l}\text { anti-seepage zone, } 2 \# \text { graded } \\
\text { aggregate }\end{array}$ \\
\hline III & Inner part & R90150W4、 $(\mathrm{C}+\mathrm{F}) / \mathrm{W} \leqslant 0.60$ & $3 \#$ graded aggregate \\
\hline IV & $\begin{array}{c}\text { Foundation at platform } \\
\text { Foundation at cut-off } \\
\text { trench }\end{array}$ & $\begin{array}{c}\text { C9020W6、 } \mathrm{C} / \mathrm{W} \leqslant 0.60 \\
\text { R90200W6、 }(\mathrm{C}+\mathrm{F}) / \mathrm{W} \leqslant 0.50\end{array}$ & $\begin{array}{l}\text { 2\# graded aggregate } \\
\text { conventional concrete } \\
\text { 2\# graded aggregate } \\
\text { Grout Enriched RCC }\end{array}$ \\
\hline V & $\begin{array}{l}\text { Upstream face } \\
\text { Downstream face }\end{array}$ & $\begin{array}{ll}\text { R90200W6、 } & (\mathrm{C}+\mathrm{F}) / \mathrm{W} \leqslant 0.45 \\
\text { R90200W6、 } & (\mathrm{C}+\mathrm{F}) / \mathrm{W} \leqslant 0.45\end{array}$ & $\begin{array}{l}\text { 2\# graded aggregate } \\
\text { Grout Enriched RCC }\end{array}$ \\
\hline
\end{tabular}

NOTE: $\mathrm{C} / \mathrm{W}$ refers to the ratio of cement to water, $(\mathrm{C}+\mathrm{F}) / \mathrm{W}$ refers to the ratio of cement plus admixture to water.

\subsection{RCC mix proportion and benefit analysis}

Determination of RCC mix proportion is a very important part of the work to ensure the quality and durability of the dam ${ }^{[10]}$. For high and medium-height dams, the concrete mix proportion generally needs to be determined by laboratory tests and field compaction tests. By laboratory tests, we measure the temperature, consistency, density and air content of fresh mixed concrete, and produce specimens for compressive strength tests, and then measure the strength of the concrete aged $7 \mathrm{~d}, 14 \mathrm{~d}, 28 \mathrm{~d}$, 56d, 90d, 120d, 180d and 365d, etc., which will show the characteristics of strength growth with age. Laboratory tests can also find out the static elastic modulus and Poisson's ratio at a given age. Although laboratory tests can work out a mix proportion that meet the requirements for on-site concrete batching, mixing and placing, due to the differences in weighing accuracy, mixing equipment size, mixing method and other factors, as well as the changes in raw materials, aggregate gradation, compaction equipment, concrete curing conditions, placement time, etc., it is difficult to simulate the on-site working conditions in laboratory. Therefore, the final concrete mix proportion is to be determined on the basis of on-site compaction tests, using the raw materials and equipment actually used in construction. The concrete mix proportion for each zone of the dam, obtained by on-site compaction tests, are shown in Table 2.

After obtaining concrete mix proportion for each zone, we can carry out the economic analysis (including unit cost and major parameters such as the amount of cement, fly ash, cementitious materials and water, fly ash percentage and water to cement plus admixture ratio) . The parameters of per cubic meter concrete of each zone and unit costs are listed in Table 3. Table 3 shows that the RCC cementitious material needed in each zone is greater than $150 \mathrm{~kg} / \mathrm{m}^{3}$, which is in the high range of cementitious material content. The $\mathrm{VC}$ value of the concrete mixed by these proportions is low, so it is suitable for construction in the hot season, easy to compact, and good in impermeability property. But its shortcoming is that it produces relatively more heat, it requires temperature control during the placement and careful curing afterwards.

Table 2. Concrete mix proportion for each zone of the dam

\begin{tabular}{|c|c|c|c|c|c|c|c|c|c|}
\hline Grade & $\begin{array}{l}\text { Water } \\
(\mathrm{kg})\end{array}$ & $\begin{array}{c}\text { Cement } \\
(\mathrm{kg})\end{array}$ & $\begin{array}{c}\text { Fly ash } \\
(\mathrm{kg})\end{array}$ & $\begin{array}{l}\text { Sand } \\
(\mathrm{kg})\end{array}$ & $\begin{array}{c}\text { Small } \\
\text { aggregate } \\
(\mathrm{kg})\end{array}$ & $\begin{array}{l}\text { Medium- } \\
\text { size } \\
\text { aggregate } \\
\quad(\mathrm{kg})\end{array}$ & $\begin{array}{c}\text { Big } \\
\text { aggregate } \\
(\mathrm{kg})\end{array}$ & $\begin{array}{l}\text { Water } \\
\text { reducer } \\
(\mathrm{kg})\end{array}$ & $\begin{array}{c}\text { Air- } \\
\text { entraining } \\
\text { agent } \\
(\mathrm{kg})\end{array}$ \\
\hline $\mathrm{R}_{90} 200 \mathrm{RCC}$ & 99 & 99 & 121 & 785 & 669 & 669 & / & 2.2 & 0.176 \\
\hline $\mathrm{R}_{90} 150 \mathrm{RCC}$ & 89 & 71 & 107 & 724 & 441 & 588 & 441 & 1.78 & 0.142 \\
\hline R90200 Grout Enriched RCC & 124 & 125 & 153 & 785 & 669 & 669 & / & 2.78 & 0.176 \\
\hline $\mathrm{C}_{90} 20$ Conventional concrete & 140 & 224 & 56 & 694 & 645 & 645 & & 2.24 & 0.025 \\
\hline
\end{tabular}

Table 3. Parameters of per cubic meter concrete of each zone and unit costs

\begin{tabular}{|c|c|c|c|c|c|c|c|}
\hline Grade & $\begin{array}{l}\text { Cement } \\
(\mathrm{kg})\end{array}$ & $\begin{array}{c}\text { Fly ash } \\
(\mathrm{kg})\end{array}$ & $\begin{array}{c}\text { cementitious } \\
\text { material }\end{array}$ & $\begin{array}{c}\text { Fly ash } \\
\text { percentage } \\
(\%)\end{array}$ & $\begin{array}{c}\text { Water } \\
(\mathrm{kg})\end{array}$ & $\mathrm{W} /(\mathrm{C}+\mathrm{F})$ & $\begin{array}{l}\text { Unit cost } \\
\text { (yuan) }\end{array}$ \\
\hline $\mathrm{R}_{90} 200 \mathrm{RCC}$ & 99 & 121 & 220 & 55 & 99 & 0.45 & 322.21 \\
\hline $\mathrm{R}_{90} 150 \mathrm{RCC}$ & 71 & 107 & 178 & 60 & 89 & 0.50 & 305.63 \\
\hline R90200 GroutEnriched RCC & 125 & 153 & 278 & 55 & 124 & 0.45 & 385.48 \\
\hline
\end{tabular}




\section{\begin{tabular}{l|l|l|l}
\hline C9020 conventional concrete & 224 & 56 & 280 \\
\hline
\end{tabular} \\ Table 3 also shows that, in comparison, the amount of cement in the $\mathrm{C}_{90} 20$ roller compacted concrete is about $125 \mathrm{~kg} / \mathrm{m}^{3}(125=224-99)$ less than that in the $\mathrm{C}_{90} 20$ conventional concrete, the former is only $55.8 \%(55.8 \%=125 / 224)$ of the latter. The calculation formula for the absolute temperature increment of concrete ${ }_{0}$ is ${ }^{[14]}$ :

$$
\theta_{0}=\frac{Q_{0} W}{C_{c} \gamma_{c}}
$$

Where $\mathrm{Q}_{0}$ represents the final heat of hydration of cementitious materials, $\mathrm{kJ} / \mathrm{kg}$; W represents cementitious material consumption, $\mathrm{kg} / \mathrm{m}^{3} ; C_{c}$ represents concret specific heat, $\mathrm{kJ} / \mathrm{kg} \cdot{ }^{\circ} \mathrm{C} ; \quad{ }_{c}$ is concrete unit weight, $\mathrm{kg} / \mathrm{m}^{3}$. By the formula (1), we know that the absolute temperature increment of concrete is proportional to the amount of cementitious materials, because the RCC uses less cementitious material, it can greatly reduce the internal temperature rise in the dam, thus simplifying the temperature control measures. Furthermore, the RCC can facilitate high level of mechanization of concrete construction, and shorten the construction period. As analysis results, the RCC unit cost is 121.76 yuan $/ \mathrm{m}^{3}$ $(121.76=443.97-322.21)$ lower than that of conventional concrete. Total quantity of RCC of this project is $138,000 \mathrm{~m}^{3}$, and 16,802,900 yuan of cost can be saved. Therefore, it not only ensures quality and safety, but also achieves obvious economic benefits.

\subsection{Construction Problems and Solutions}

Although the needs of the construction process has been taken into consideration in the zoning of the dam concrete, construction planning must be carefully made before construction, so as to ensure that the construction can be carried out according to the designed concrete zones. If it is difficult to meet the designed requirements due to the restriction of construction conditions, it is necessary to have a review of the original design, make necessary adjustments, and propose appropriate solutions. During the construction phase of this project, the major difficulties encountered and solutions are as follows:

(1) In comparison, the RCC can significantly reduce the internal heat of hydration of the dam, lower its temperature, but due to its high speed of construction and the big volume of a single placement, the concrete hydration heat has no time dissipate. In addition, by nature, the RCC's process of temperature rise is longer than that of conventional concrete. Because of tight schedule, the peak of RCC construction period of this project has to be arranged in the hot season from May to September, therefore more attention must be paid to the temperature control. According to the results of temperature-control calculation and analysis, the placing temperature of RCC should not exceed $28{ }^{\circ} \mathrm{C}$. If the placing temperature can not meet the requirement, take the following measures: (1) Run the cooling system to pre-cool the water and aggregate to be mixed; (2) Try to avoid high temperature period in daytime, place in the period from evening to next morning; (3) Make an artificial micro-climate by spraying water at the lift surface, so as to reduce its surface temperature. (4) After compaction and before placing the next layer, keep the surface wet for 24 hours round the clock, and cure the last layer at the top not less than 14 days. The scene of $\mathrm{RCC}$ construction is shown in Figure 3.

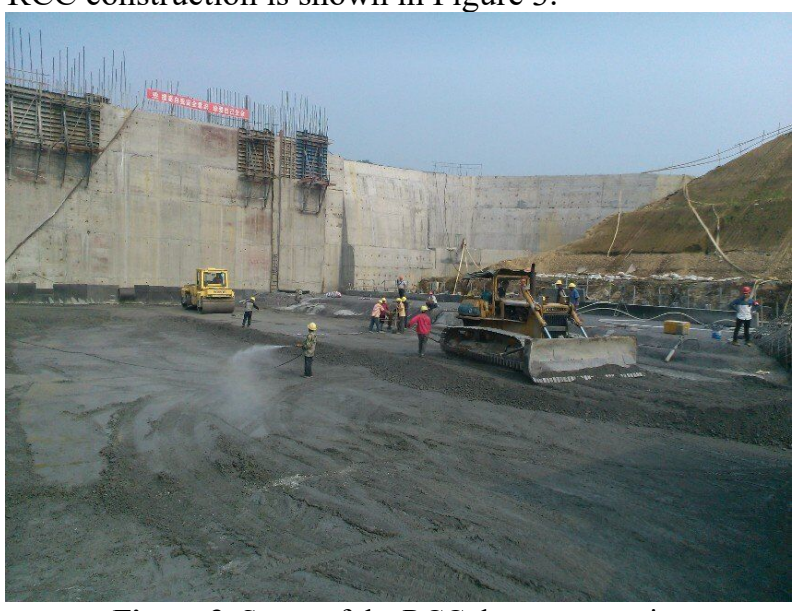

Figure 3. Scene of the RCC dam construction.

(2) Generally, a space is reserved as the entrance for compaction machinery to move into the working face. Only after RCC compaction is completed can we start to fill the gap with conventional concrete. Thus a small part of the concrete at the entrance shall not be placed as designed for the zone, and it is difficult to ensure its quality. During the construction of the conventional concrete at the entrance, ice is added into the mixing water, so as to lower the concrete placing temperature and reduce the impact of solidification heat of conventional concrete on the internal temperature field of the dam. In addition, in the construction process, cover the completed RCC with protective pad to prevent the damage by the machinery traffic, and re-compact it to repair the damage, because the repeated forceful pressing by the machinery may damage the internal cementitious structure and reduce the strength of concrete.

(3) Curtain Grouting gallery is arranged just at the downstream side of the upstream impervious concrete face. The impervious concrete thickness is about 3 meters. Due to the existence of gallery, the working face at the upstream of the gallery is very narrow, it is impossible to carry out RCC construction. Hence, the concrete at the upstream of gallery shall be changed to conventional concrete. When it reaches up to 1 meter above the top of gallery, its working face shall be combined with that of the dam's internal part, and from then on it shall be the RCC. Similarly, when placing the conventional concrete at the upstream of the gallery, ice is added into the mixing water, so as to lower the concrete placing temperature and counteract the impact by the solidification heat produced in conventional concrete, which is more than that in the RCC.

(4) In the placement of concrete, use large cantilevered steel formwork, which is 3 meters high, can be easily and precisely installed, and easily removed. 
But, at the dam's inclined downstream face, in the area near the forms, no compaction can be carried out. The concrete in such an area has be replaced with Grout Enriched RCC (GE-RCC). The thickness of the GE-RCC is increased, so is the cost. In addition, because the GERCC uses a larger amount of cement, it demands more temperature control efforts. This problem is partly solved by the use of precast concrete blocks as the formwork, or by the use of smaller steel formwork, which reduces the height of the formwork.

(5) According to the requirement of the RCC gravity dam, the transverse joints are arranged at an interval of 25 meters, which is greater than the required interval specified in the concrete gravity dam design code. Because of the construction process requirements, some parts of the dam, such as Zone I, have to use conventional concrete. During its hardening process, shrinkage of conventional concrete is relatively high. When contracting, the newly placed concrete is in the state of tension, because of the constraints by the dam body at its bottom. So the newly placed concrete is prone to transverse cracks. During the construction, the following measures have been taken to address this problem: (1) Treat the emerged cracks with chemical grouting, of which grouting material has high strength, and ensure that after grouting it meets the designed strength and anti-seepage requirements; (2) Optimize concrete mix proportions, using the $3 \#$ Graded Aggregate Concrete for the central area, so as to reduce concrete shrinkage in hardening process; (3) Arrange $12 @ 200 \times 200$ anti-crack steel meshes in the central section of the dam at every lift of placement, and stipulate that each lift of concrete should not be less than 1 meter. After anti-crack steel meshes was arranged, cracks did not emerge again in the conventional concrete placed at the top of the dam. The photograph in Figure 4 shows the anti-crack steel meshes arranged in the Concrete Zone 1.

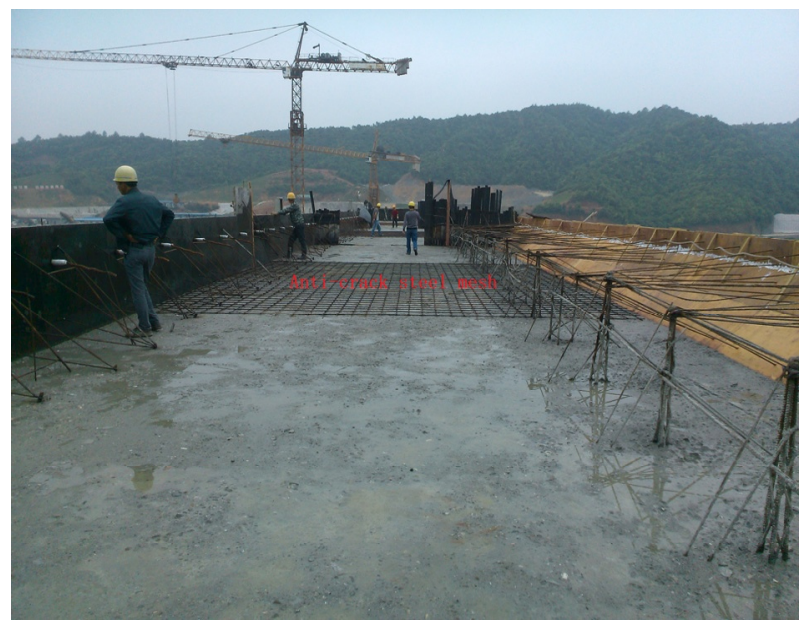

Figure 4 Anti-crack steel mesh arranged in the Concrete Zone 1

\section{Conclusions}

Based mainly on the design and construction process of the RCC gravity dam of Jiangxi Wuxikou Hydropower Project design, this paper discusses how to zone the
RCC gravity dam and design the zones, what problems in the construction should be noted and how to solve the special problems encountered. The main conclusions are listed as follows:

(1) The zoning of a RCC dam should be made according to the design codes and regulations, as well as its own characteristics and the needs of the construction. For example, according to the characteristics of each concrete zone, make some little changes to solve practical problems such as water-stop embedding and construction positioning. In terms of the designed concrete zones, the RCC gravity dam of Wuxikou Hydropower Project is a typical representative, as the zoning significantly reduces the amount of cementitious material, alleviates the temperature-control burden, and makes full advantage of high-degree mechanization and short construction period of the RCC dam. The design obtains significant benefits in economic aspect and construction time.

(2) At the construction phase of the RCC gravity dam, there should be careful construction planning, taking into consideration of the location of the entrance to the construction face, selection of the formwork, order of concrete placing and compaction, measures of temperature control, and so on. The construction of the RCC dam of this project overcomes difficulties in external conditions such as unfavorable construction schedule. For technical reasons, the designed zones of dam have been modified. A careful analysis of its consequences has been made, and an effective measure has been proposed. While ensuring the safety of the project quality, it helps achieve the objective of completion on schedule. Currently, the RCC dam construction is substantially completed, the analysis of the problems that emerged in process of construction may be a useful reference for future similar projects.

\section{References}

1. SI Zhi-ming, QIN Gen-quan. Design and construction technology development and case studies of RCC gravity dams[M]. Beijing: China Water and Power Press, 2014. (in Chinese)

2. Gaspar A, Lopez F. Methodology for a probabilistic analysis of an RCC gravity dam construction. Modelling of temperature, hydration degree and ageing degree fields[J]. Engineering Structures, 2014, 65(3): 99-110.

3. Carvajal C, Peyras L, Bacconnet C, Bécue J P. Probability modelling of shear strength parameters of RCC gravity dams for reliability analysis of structural safety[J]. European Journal of Environmental \& Civil Engineering, 2009, 13(1): 91119.

4. LIU Yi-song, CHEN Deng-hong. Finite element analysis of Longtan RCC gravity dam[J]. Yangtze River, 2007, 38(1): 36-38. (in Chinese))

5. HUANG Shu-ping, WU Xu, SHI Duan-xue, et al. Feasibility study on continuous RCC placement for constr uction of Longtan RCC Gravity Dam[J]. 
Water Resourc es and Hydropower Engineering, 2006, 37(5): 59-62. (in Chinese)

6. WANG Bing-jun. Design of left bank RCC dam at Tongjiezi Hydropower Station[J]. Design of Hydroelectric Power Station, 1988, (3): 83-89. (in Chinese)

7. LI Di-guang, WANG En-hong, Mao Lian-fu. Concrete partition and mix proportion optimum design for concrete dam at Jinanqiao hydropower Station[J]. Yunnan Water Power, 2012, 28(4): 70-72. (in Chinese)

8. CHEN Qiang, LIAO Gui-ying, YAN Yong. Introduction of roller compacted concrete gravity dam design at Guandi Hydropower Station[J]. Design of Hydroelectric Power Station, 2013, 29(3): 5-8. (in Chinese)

9. ZHAO Chun-ju, ZHOU Yi-hong. Simulation research on construction course of Longkaikou Roller Compacted Concrete Gravity Dam[J]. Hubei Water Power, 2008, Super: 14-20. (in Chinese)
10. LIN Jia-hua, JIANG Chang-quan, LI Ji-hai. Features of Jiangya dam RCC mix proportion[J]. Yangtze River, 1999, 30(6): 20-21. (in Chinese)

11. Ministry of Water Resources of the People's Republic of China. SL 314-2004. Design specification for roller compacted concrete dams[S]. Beijing: China Water Conservancy, 2004. (in Chinese)

12. WANG Tao. Jiangxi Wuxikou hydro project entered the construction phase[J]. China Water Conservancy, 2013, (11): 80-80. (in Chinese)

13. LIANG, Bi-jue, CHEN Chang-jiu. Brief analysis on application of rock-filled concrete to construction of guide wall[J]. Water Resources and Hydropower Engineering, 2014, 45(7): 57-59. (in Chinese)

14. Ministry of Water Resources of the People's Republic of China. SL 319-2005. Design specification for concrete gravity dams[S]. Beijing: China Water Conservancy, 2005. (in Chinese) 